\title{
Transtorno do Espectro Autista: ressonâncias emocionais e ressignificação da relação mãe-filho
}

\section{Autistic Spectrum Disorders: emotional resonances and ressignification of the mother-son relationship}

Hiara de Bodas Lopes ${ }^{1}$, Ildaiane Cristine de Meneses², Ellen Fernanda Klinger $^{3}$, Jaqueline Suzuki ${ }^{4}$

\section{RESUMO}

O Transtorno do Espectro Autista (TEA) é uma psicopatologia cujos sinais estão presentes nos primeiros 36 meses de vida da criança, tendo como características manifestações na esfera comportamental, déficits na comunicação e interação social, padrões de comportamentos repetitivos e estereotipados e repertório restrito de interesses e atividades. Tais sintomas podem se apresentar em menor ou maior grau de comprometimento e afetam o indivíduo com o transtorno e as pessoas diretamente envolvidas no seu cuidado. Este estudo objetivou compreender as repercussões emocionais vivenciados pela mãe. Para a coleta de dados, foram realizadas entrevistas semiestruturadas e aplicados os Inventários Beck de Depressão, Ansiedade e Desesperança, com mães de crianças autistas. As escalas foram analisadas e as entrevistas foram transcritas, sendo empregada a análise de conteúdo. Dentre os resultados, destacaram-se como sentimentos mais presentes durante a investigação, e após o fechamento do diagnóstico o desespero, tristeza, desanimo e culpa. Após o choque inicial do diagnóstico e o luto diante da nova perspectiva, a necessidade de ressignificação da relação com o filho. O acompanhamento e suporte profissional desde - momento que precede o diagnóstico, suspeita, durante e após se fazem imprescindíveis tanto as crianças autistas, quanto para os familiares, em especial à mãe.

Palavras-chave: Família. Diagnóstico. Autismo.

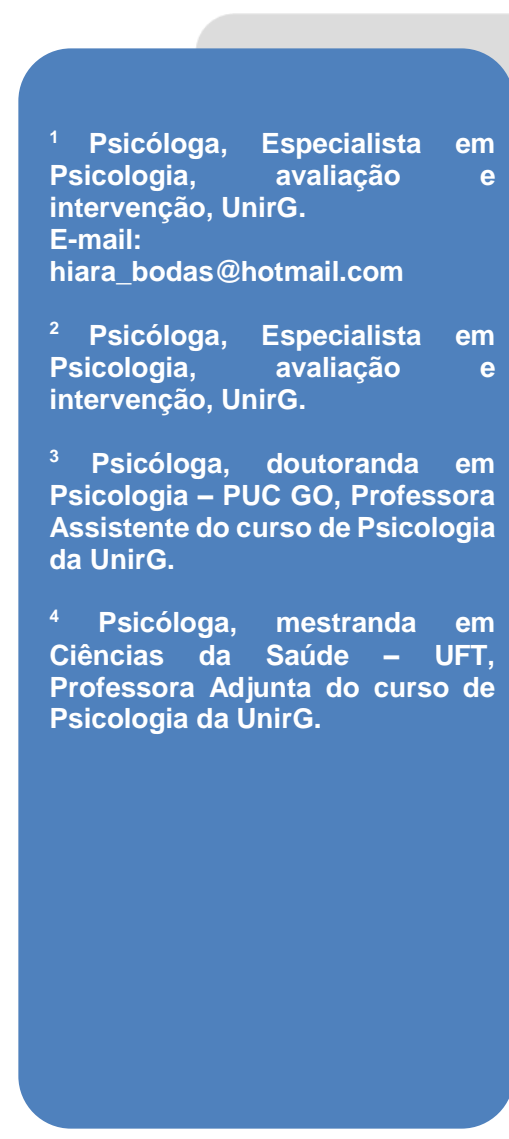

\section{ABSTRACT}

Autistic Spectrum Disorders (ASD) is a psychopathology whose signs present they ware in the first 36 months of the child's life, having as characteristics manifestations in the behavioral sphere, deficits in communication and social interaction, patterns of repetitive and stereotyped behaviors and a restricted repertoire of interests and activities. Such symptoms may present to a lesser or greater degree of impairment and affect not only the individual with the disorder and those directly involved in their care. This study aimed presented as repercussions and unfolding of emotional experiences experienced by the mother. Semi-structured interviews and application of the Beck Inventories of Depression, Anxiety and Hopelessness, with mothers. The scales were analyzed and the interviews were transcribed, using content analysis with thematic axes. The most present feelings during the investigation, and after the closing of the diagnosis were: despair, sadness, discouragement and guilt. After the initial shock of diagnosis and mourning, the need to redefine the relationship and look at the child. The professional support from the moment that precedes the diagnosis, suspect, during and after are essential, both autistic children and family members, especially the mother.

Keywords: Family. Diagnosis. Autism. 


\section{INTRODUÇÁO}

O autismo está em evidência em âmbito nacional, tornando-se temática para políticas públicas na área da saúde e da educação. Em 2012, foi sancionada a Lei no 10.764 que instituiu a Política Nacional de Proteção dos Direitos da Pessoa com Transtorno do Espectro Autista (BRASIL, 2012) e, em 2014, o Ministério da Saúde lançou as Diretrizes de Atenção à Reabilitação da Pessoa com Transtornos do Espectro do Autismo (BRASIL, 2014).

O Transtorno do Espectro Autista (TEA) é considerado uma síndrome neuropsiquiátrica caracterizada por manifestações comportamentais acompanhadas por déficits na comunicação e interação social, padrões de comportamentos repetitivos e estereotipados e um repertório restrito de interesses e atividades. Tais aspectos envolvendo essa tríade de características podem ser detectados nos primeiros três anos de vida e persistir ao longo da vida afetando, inclusive, as pessoas mais próximas ao autista e que estão diretamente envolvidas em seus cuidados (JERUSALINSKY et al., 2013; GOMES et al., 2015).

Somada a essas dificuldades, inúmeras pessoas com autismo também se deparam com limitações na realização de atividades corriqueiras, como higiene e alimentação, as quais podem estar associadas aos comportamentos rígidos, agressivos ou repetitivos apresentados por eles. Em decorrência disso, a necessidade de cuidados diferenciados e a dependência dos pais e demais cuidadores é acentuada, levando a família a constantes mudanças na sua rotina a fim de se adaptar às características do familiar com autismo (FÁVERO \& SANTOS, 2005; SCHMIDT et al., 2007; SMEHA \& CEZAR, 2011; CEZAR \& SMEHA, 2016).

O Autismo e a síndrome de Asperger são os mais conhecidos entre os transtornos invasivos do desenvolvimento (TID), uma família de condições marcadas pelo início precoce de atrasos e desvios no desenvolvimento das habilidades sociais, comunicativas entre outras. Essas condições são caracterizadas por uma grande variabilidade de apresentações clínicas, tanto em relação ao perfil da sintomatologia quanto ao grau de acometimento, mas são agrupados por apresentarem em comum uma interrupção precoce dos processos de sociabilização, consequentemente, ocorre uma interrupção dos processos normais de desenvolvimento social, cognitivo e da comunicação (KLIN, 2006).

As manifestações comportamentais são heterogêneas e há diferentes graus de acometimento, e provavelmente múltiplos fatores etiológicos, daí a origem do termo 
transtornos do espectro do autismo que, como o termo TID, refere-se a várias condições distintas (autismo, síndrome de Asperger e TID-Sem outra Especificação), mas que, ao contrário do termo TID, refere-se a uma possível natureza dimensional que interconecta diversas condições mais do que a fronteiras claramente definidas em torno de rótulos diagnósticos. Este conceito de natureza dimensional apoia-se no fato de que o autismo e transtornos relacionados são os transtornos do desenvolvimento mais fortemente associados a fatores genéticos, e no fato de que podem ser encontradas vulnerabilidade e rigidez social em familiares desses pacientes, mesmo que esses familiares não preencham critérios para um diagnóstico clínico (KLIN, 2006).

O diagnóstico de TEA é essencialmente clínico, feito a partir das observações na criança, entrevistas com os pais e aplicação de instrumentos específicos. Os critérios usados para diagnosticar o TEA são descritos no Manual Estatístico e Diagnóstico da Associação Americana de Psiquiatria, o DSM-V (APA, 2014). Esses critérios têm evoluído com o passar dos anos. O DSM-V, lançado nos EUA em maio de 2013, compõe o mais novo instrumento para guiar o diagnóstico médico dos indivíduos com TEA. Além desse manual, há outros testes de rastreamento para o TEA, como, por exemplo, a Escala de Classificação de Autismo na Infância, Indicadores Clínicos de Risco para o Desenvolvimento Infantil e ModifiedChecklist for Autism in Toddlers (GOMES et al., 2015).

A descoberta de uma patologia, deficiência ou alteração em uma criança traz repercussões na vida dos pais e, frequentemente, também mudanças significativas na vida das mães, que assumem a responsabilidade de cuidar da criança (SEREGEM\& FRANÇOZO, 2014). A partir disso, a pesquisa partiu do pressuposto de que o diagnóstico de TEA causa alterações na dinâmica familiar e que mães de crianças com o transtorno sentem-se emocionalmente abaladas e desamparadas após o diagnóstico, podendo apresentar traços de depressão, ansiedade e/ou desesperança. Nesse sentido, a pesquisa buscou compreender as repercussões emocionais vivenciados pela mãe, estendendo-se a família, diante do diagnóstico de Transtorno do Espectro Autista do filho

\section{MATERIAIS E METODOS}

Trata-se de um estudo descritivo-exploratório, com abordagem qualitativa. A coleta de dados deste estudo iniciou-se após autorização da Associação de Pais, Amigos e Profissionais dos Autistas do Estado do Tocantins - Anjo Azul, na cidade de Palmas - TO, e a aprovação do Comitê de Ética em Pesquisa com seres humanos, CAAE no 
58836216.1.0000.5518. A associação supracitada foi fundada há quatro anos e visa auxiliar as mães, sanar dúvidas de familiares, promover a divulgação, informar e conscientizar a população sobre como lidar melhor com o Transtorno do Espectro Autista. Atualmente conta com vários profissionais voluntários e as reuniões com os familiares e amigos ocorrem periodicamente.

A partir da autorização da Associação, e após apresentação e assinatura da Carta de Autorização para a realização da pesquisa, as pesquisadoras entraram em contato com as cinco mães de indivíduos com autismo indicadas pela associação, convidando-as a participarem voluntariamente da pesquisa, podendo retirar-se da mesma a qualquer momento, os horários, datas e local foram agendados previamente de acordo com disponibilidade das entrevistadas. A amostra de 5 (cinco) mães, refere-se ao número de mães levantado junto à associação que se enquadraram nos critérios de inclusão e exclusão, que são: tempo de diagnóstico do TEA entre 6 (seis) e 36 (trinta e seis) meses, e que aceitaram e assinaram o Termo de Consentimento Livre Esclarecido (TCLE).

Foram realizadas entrevistas semiestruturadas, compostas por 10 (dez) questões dissertativas formuladas pelas pesquisadoras que tem como objetivo responder ao problema da pesquisa. Essas foram gravadas em áudio, com autorização das mães, a fim de facilitar a interação com os sujeitos investigados e fidedignidade das respostas para a transcrição e análise dos dados.

Após a entrevista, as mães responderam a um teste psicológico, as Escalas Beck, utilizando o Inventário de Beck de Ansiedade (BAI), o Inventário de Beck para Depressão (BDI), e a Escala de Desesperança de Beck (BHS). No BAI, a soma dos escores identifica o nível de ansiedade, tendo a seguinte classificação: zero a 10 - Mínimo; 11 a 19 - Leve; 20 a 30 - Moderado e 31 a 63 - Grave. No BDI a soma dos escores identifica o nível de depressão, com a seguinte classificação: zero a 11 -Mínimo;12 a 19- Leve; 20 a 35 Moderado e 36 a 63 - Grave. No BHS, a soma dos escores identifica o nível de desesperança, cujos escores variam de 0 a 20 e tem a seguinte classificação: zero a 4Mínimo; 5 a 8 - Leve; 9 a 13 - Moderado e 14 a 20 - Grave.

Todos os dados obtidos através das entrevistas e das Escalas Beck foram usados exclusivamente para fins da pesquisa em questão, garantindo assim a preservação e total integridade dos sujeitos nela envolvidos. A correção dos dados das Escalas foi efetuada com o uso do manual do referido teste psicológico, por duas psicólogas preparadas para tal função. A fim de preservar a identidade das participantes foram adotadas as letras $M$ 
seguidas de numeral para as mães e F seguida de numeral para os filhos, ficando, por exemplo $\mathrm{M} 1$ e respectivamente $\mathrm{F} 1$.

As entrevistas com as mães foram transcritas e analisadas de acordo com os parâmetros da Análise de Conteúdo (BARDIN, 2011). Nesta técnica, realizou-se sucessivas leituras e releituras do material produzido, buscando identificar conteúdos emergentes nos relatos dos entrevistados e organizá-los de modo coerente com os objetivos da pesquisa. Conforme Minayo (2007), existem várias modalidades de análise de conteúdo, logo nesta pesquisa foi utilizada a Análise Temática, por ser a mais simples e a melhor que se encaixa para as investigações qualitativas em saúde.

A análise temática ocorre em três etapas distintas: pré-análise; exploração do material e; tratamento dos resultados obtidos. Os procedimentos a serem seguidos nessa metodologia de análise de dados consistem na ordenação dos dados a partir das informações contidas na coleta de dados e posterior mapeamento de todos os dados; classificação dos dados, para leitura do material e identificação dos temas relevantes e estabelecimento das categorias temáticas; análise final realizando a articulação entre os dados e as referências teóricas adotadas (MINAYO, 2007).

\section{RESULTADOS E DISCUSSAOO}

A partir da análise das entrevistas emergiram quatro categorias: Sentimentos e vivências; Ressignificação do filho; Mudanças na família e mãe: configuração familiar; e Rede de apoio, das quais as duas primeiras serão apresentadas e discutidas neste artigo.

Os dados sóciodemográficos das tabelas, nortearam a pesquisa apontando os critérios de inclusão e exclusão da mesma. Na Tabela 1 é possível perceber, que independente do nível de escolaridade de cada mãe, elas não tinham conhecimentos aprofundados sobre o autismo. Todas relatam que buscaram investigar o que era o autismo 
para que a partir daí, passassem a entender melhor o comportamento do filho(a) e então, ajudá-lo(a).

\section{MÃES}

\begin{tabular}{|c|c|c|c|c|c|}
\hline DADOS & M1 & M2 & M3 & M4 & M5 \\
\hline Idade & 36 & 40 & 29 & 33 & 35 \\
\hline Escolaridade & $\begin{array}{l}\text { Superior } \\
\text { Completo }\end{array}$ & $\begin{array}{l}\text { Superior } \\
\text { Completo }\end{array}$ & $\begin{array}{l}\text { Ensino médio } \\
\text { completo }\end{array}$ & $\begin{array}{l}\text { Superior } \\
\text { Completo }\end{array}$ & $\begin{array}{l}\text { Superior } \\
\text { Completo }\end{array}$ \\
\hline Renda & $\begin{array}{c}4 \text { a } 7 \\
\text { salários } \\
\text { mínimos }\end{array}$ & $\begin{array}{l}4 \text { a } 7 \text { salários } \\
\text { mínimos }\end{array}$ & Não quis falar & $\begin{array}{l}\text { Acima de } 8 \\
\text { salários } \\
\text { mínimos }\end{array}$ & $\begin{array}{l}3 \text { salários } \\
\text { mínimos }\end{array}$ \\
\hline № de Filhos & 02 & 02 & 01 & 01 & 02 \\
\hline $\begin{array}{l}\text { № de Pessoas } \\
\text { que residem na } \\
\text { mesma casa }\end{array}$ & 04 & 04 & 03 & 03 & 04 \\
\hline $\begin{array}{l}\text { Tempo de } \\
\text { diagnóstico }\end{array}$ & 20 meses & 28 meses & 36 meses & 19 meses & 18 meses \\
\hline $\begin{array}{l}\text { Conhecimento } \\
\text { sobre o autismo } \\
\text { antes do } \\
\text { diagnóstico }\end{array}$ & $\begin{array}{l}\text { Sim, } \\
\text { superficial }\end{array}$ & $\begin{array}{l}\text { Sim, muito } \\
\text { pouco }\end{array}$ & $\begin{array}{c}\text { Nenhum } \\
\text { conhecimento }\end{array}$ & $\begin{array}{l}\text { Sim, muito } \\
\text { pouco }\end{array}$ & $\begin{array}{l}\text { Sim, muito } \\
\text { pouco }\end{array}$ \\
\hline
\end{tabular}

\subsection{SENTIMENTOS E VIVÊNCIAS}

Os pais com filhos autistas passam por sentimentos como os de: negação, frustração, culpa, medo, impotência, solidão, ressentimento, raiva, rejeição. Ter uma criança "diferente" gera um sentimento de culpa muito grande nos pais, mesmo que amem seu filho e tenham feito o melhor por ele (BORALLI, 2014). Diante dos relatos trazidos pelas 
mães, é possível identificar alguns destes sentimentos vivenciados por elas após o diagnóstico e no decorrer do processo de aceitação.

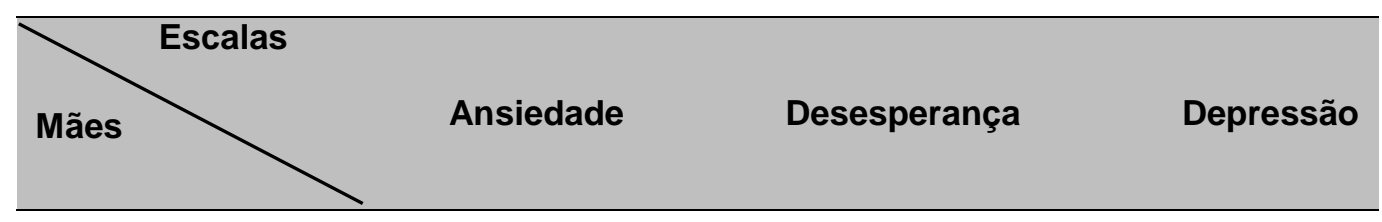

$\begin{array}{lccc}\text { M1 } & 0 & 1 & 4 \\ \text { M2 } & 14 & 1 & 13 \\ \text { M3 } & 29 & 7 & 24 \\ \text { M4 } & 9 & 0 & 5 \\ \text { M5 } & 28 & 15 & 29\end{array}$

Tabela 2 - Escores das Escalas Beck

Nas escalas Beck utilizadas para mensurar os níveis de ansiedade, depressão e desesperança, foi possível perceber que os sentimentos mais presentes nas mães foram os de ansiedade e depressão. Sendo que, desesperança apareceu mais acentuada somente em duas mães. E diante destes sentimentos, as mesmas afirmaram que no momento que receberam o diagnóstico, esses sentimentos eram bem mais alarmantes do que no momento em que foram submetidas às escalas. Diante dos relatos e dos resultados das escalas as mães se sentem vivenciando um período confuso e dolorido, chegando então, a ter medo do futuro e dos enfretamentos necessários após o diagnóstico.

Enfrentar esse momento coloca em jogo as emoções e os sentimentos da mãe, que, embora vivenciando uma situação adversa, almeja em meio a esse turbilhão de sentimentos, dar continuidade ao seu ser mãe de uma criança com deficiência, buscando 
alternativas de adaptação a essa realidade (BARBOSA, CHAUD \& GOMES, 2008). Sobre estes sentimentos, os relatos das mães são fidedígnos:

"Então, o medo né, de encarar uma realidade que é difícil... dificuldades, discriminação, então a gente fica sempre amedrontado..." (M2).

"Primeiro a gente fica muito mal emocionalmente... me dava desespero...um processo punitivo que a gente entra, é um processo meio maluco..." (M4).

Um dos momentos considerados mais críticos para a família é o momento do diagnóstico, pois se por um lado o diagnóstico vem acompanhado do alívio, por saber o que seu filho tem e como pode ajudá-lo, do outro vem o choque de saber que o filho tem uma "doença crônica”, com a qual a família terá que aprender a lidar (OLIVEIRA et al., 2014).As mães participantes da pesquisa, embora estejam sofrendo, se preocupam em estar bem para lidar com a realidade, no entanto, ainda se sentem amedrontadas e em processo de luto, ao se deparar com questionamentos internos e externos. Ainda, algumas mães relatam que o fechamento do diagnóstico foi um alívio e também, serviu para orientá-las acerca de como agir com seus filhos, permitindo a elas, elaborar uma estratégia de interação mais eficiente com a criança, de acordo com o contexto onde estão inseridas.

"[...] a partir do momento que nós soubemos, começamos a buscar como agir..." (M1).

"[...] ai quando eu voltei na médica advinha só? Senti um alívio. E isso me deu uma força, porque...Eu pensei que poderia estar colocando uma doença no meu filho." (M5).

As mães se percebem vivendo um período de luto, porém, se preocupam em superar a perda do bebê sonhado e, dessa forma, encontram força para cuidar e aceitar o filho como ele realmente é, tomando consciência de que o filho precisa de seus cuidados. Para elas, a aceitação vem com o tempo, e de acordo com a maneira como foram informadas a 
respeito do diagnóstico. As mães, ainda se sentem como pessoas escolhidas para gerarem um filho autista ou que este veio para transformar sua vida e a vida de sua família.

"[...] com o passar do tempo a gente vai tentando se acostumar com a ideia né...aceitar da melhor forma possível pra poder ajudar ela..." (M3).

"E você tem que ter sempre essa convicção, de que você foi escolhida, pelo criador pra cuidar daquele presente, porque é um presente que ele nos deu..." (M1).

“[...] Então assim, eu começo a pensar, essa criança ela veio por algum motivo, não tem alguma coisa errada aí, tudo tem um porque nessa vida...a gente tá aqui só pra obedecer..." (M4).

Desta forma, vê-se a importância das mães buscarem informações a respeito de todo o processo que estão passando com seus filhos. Pois, a falta de informação dificulta a compreensão da família sobre o Transtorno do Espectro Autista. Ademais, contar com uma rede de suporte seja grupo, amigos, profissionais, a família faz-se imprescindível nesses momentos.

“[...] Se eu continuasse naquele estado eu não poderia ajudá-lo, foi quando eu comecei a estudar, a me pós graduar, a especializar e a buscar mais conhecimento para assim ajudá-lo...” (M1).

“[...] Então, a partir de então a minha vida mudou, a minha vida é só educação especial...procurei fazer cursos né, sobre deficientes intelectuais, procurei fazer curso de libras...então eu procuro estar sempre nesse meio pra melhorar o conhecimento..." (M2).

"[...] Eu comecei uma especialização na área... Hoje eu vivo isso...só tenho pacientes autista..." (M4).

Portanto, a pesquisa indica que, a busca por conhecer melhor o Autismo, poderá oportunizar a mãe e a família novas possibilidades de atuação/interação junto à criança e diante de tais mudanças, da inserção do diagnóstico no meio familiar e na vida materna, as 
mães também sofrem modificações não só pessoais, mas em suas vidas profissionais, pois, às vezes, acabam sendo influenciadas pela busca máxima de tal conhecimento.

\subsection{RESSIGNIFICAÇÃO DO FILHO}

De acordo com Smeha \& Cezar (2011), os pais anseiam pela criança perfeita e saudável porque criam no filho a possibilidade de concretizar seus sonhos e ideais, e quando o filho possui alguma limitação significativa, suas expectativas se fragilizam, já que a criança perfeita que lhes proporcionaria alegrias não nasceu. Com essa perda, as mães vivenciam um doloroso processo de luto.

O estágio inicial de luto é de choque, acompanhado de choro, manifestando sentimentos de desamparo e ânsia por fugir; no segundo estágio, há descrença e negação da situação; no terceiro, há tristeza e ansiedade manifestada por muito choro e raiva; no quarto, há o equilíbrio, caracterizado pela admissão de que a condição existe; por último, o estágio de reorganização, mediante reintegração e reconhecimento familiar desse filho (MAIA et al., 2016). Diante do relato de uma das mães, é perceptível as fases citadas pelas autoras na vivência destas:

"[...]meu mundo desmoronou... eu chorava muito...eu queria sumir... me desapeguei do mundo. Não doutora, F5 autista? não, nunca. Um ano com crise de ansiedade...eu não parava de chorar. Desde cedo trabalhei a aceitação. A minha casa é adaptada para o F5." (M5).

Por ser, o autismo, uma síndrome onde a criança apresenta um comportamento inflexível e muitas vezes ritualístico, exige de quem cuida total dedicação. Tal condição faz com que os pais, que idealizaram uma criança saudável e perfeita apresentem um grande choque diante a realidade do diagnóstico (PINTO et al., 2016)

“[...] ele não era o meu filho da barriga, do nada ele não era aquele menino. Pra mim existe um F5 e um segundo F5...porque acho que é aquele trem do filho idealizado que chama né, o filho vai crescer... ai do nada não, ele não vai desenvolver... então é outro filho." (M5). 
Nesse sentido, compreende-se que ter um filho é um dos acontecimentos mais importantes na vida de um ser humano. Toda a família se prepara para a chegada, se prepara também para a troca de afeto, de carinho, anseia por se comunicar através do toque, do olhar. Contudo, em famílias com autistas, isto nem sempre acontece da forma esperada (SILVA\& CHAVES, 2014).

"E hoje o F5 é fofo, é meigo, meu filho não tem problema para dormir, meu filho não é seletivo, as coisas ruins de autista o F5 não tem." (M5).

"[...] Ter um filho é querer ser mãe, e o querer ser mãe implica você aceitar o seu filho independente da condição que ele tem...” (M4).

Porém, após o choque do diagnóstico e com o passar do tempo, as mães começam o processo de aceitação, aceitando seus filhos como eles realmente são e aprendendo a ajudá-los a desenvolver suas habilidades. Neste sentido, a ressignificação do filho se dá de maneira cuidadosa pela família que acolhe, pois esta, aceita o filho, independentemente de suas limitações, buscando aceitar o diagnóstico que foi inserido na família da melhor forma possível, recorrendo a intervenções que lhe pareçam mais adequadas.

\section{CONSIDERAÇOES FINAIS}

O diagnóstico do Transtorno do Espectro Autista, não é fácil de ser fechado, exigindo dos familiares uma enorme e constante busca por exames em diversos profissionais, os mais citados e mais procurados foram os: Neuropediatras, Fisioterapeutas, Psicoterapeutas, Psicopedagogos, Fonoaudiólogos e em alguns casos os Psiquiatras. Apesar da ampla variedade de profissionais que as mães e familiares passam, poucos são especialistas em Autismo ou em fechar diagnósticos precoces. Em alguns casos, as mães passaram anos acreditando que a criança estava com uma síndrome de características semelhantes à do autismo, como por exemplo: Deficiência Intelectual, e só depois de abrir outra investigação, foi possível fechar o diagnóstico de Transtorno do Espectro Autista.

Os sentimentos mais presentes durante a investigação, e depois do fechamento do diagnóstico apurados nos escores das escalas Beck foram: desespero, tristeza, desanimo e culpa. Ao se depararem com o diagnóstico e a nova realidade as mães relataram, além 
de mudanças na sua própria rotina, um momento de choque e luto pela criança idealizada, até a aceitação da real condição do filho e ressignificação do seu olhar para criança e da relação. Ainda, a busca por informações sobre o autismo, para a compreensão do transtorno e suas especificidades, bem como para a procura por tratamentos adequados também destacou-se como um aspecto importante no discurso das mães.

Destaca-se a necessidade de suporte profissional não somente para as crianças autistas, mas aos pais, em especial à mãe. Portanto, constitui-se o trabalho multi e interdisciplinar imprescindível no processo do diagnóstico e pós diagnóstico, pois, os profissionais auxiliam e norteiam mães e familiares nesse percurso, tal como, auxiliam as crianças com TEA a desenvolver suas habilidades para uma melhor vivência. Contudo, nessa pesquisa foi possível verificar que ainda existem aspectos a serem aprimorados nos campos de investigação e atendimento do TEA, como, por exemplo, a abordagem do diagnóstico com as famílias.

São poucos os estudos voltados a autistas adultos e formas de suporte a esses, sendo a preocupação com relação ao futuro das crianças uma constante na vida das mães e também preocupação das mães quanto as famílias que ainda sofrem no recebimento e no processo de elaboração do diagnóstico. Portanto, a necessidade de pesquisas empíricas abrangendo a investigação e intervenção terapêutica com essa população.

\section{REFERENCIAS}

APA - Associação Americana de Psiquiatria. DSM-V: Manual Diagnóstico e estatístico de transtorno mentais. Porto Alegre: Artmed, 2014.

BARBOSA, M. A. M.; CHAUD, M. N.; GOMES, M. M. F. Vivências de mães com um filho deficiente: um estudo fenomenológico. Acta paul. enferm., São Paulo, v. 21, n. 1, p. 4652, mar. $2008 . \quad$ Disponível em:<http://www.scielo.br/scielo.php?script=sci_arttext\&pid=S0103$21002008000100007 \&$ Ing=pt\&nrm=iso >. Acessos em: 20 nov. 2017.

BARDIN, L. Análise de conteúdo. Lisboa: Edições 70, 2011.

BORALLI, E. R. Autismo: Trabalhando com a criança e com a família. Livro 3ª ed. São Paulo: Edicon, 2014.

BRASIL. Lei no 10.764, de 27 de dezembro de 2012. Institui a Política Nacional de Proteção dos Direitos da Pessoa com Transtorno do Espectro Autista; e altera o $§ 3^{\circ}$ do art. 98 da Lei no 8.112, de 11 de dezembro de 1990. Diário Oficial [da] República Federativa do Brasil, Brasília, DF, 2012. 
BRASIL. Ministério da Saúde. Secretaria de Atenção à Saúde. Departamento de Ações Programáticas Estratégicas. Diretrizes de Atenção à Reabilitação da Pessoa com Transtorno do Espectro Autista (TEA). Brasília: Ministério da Saúde, 2014.

CEZAR, P. K.; SMEHA, L. N. Repercussões do autismo no subsistema fraterno na perspectiva de irmãos adultos. Estud. Psicol.,v. 33, n. 1, p. 51-60, Mar. 2016. Disponível em: $<$ http://www.scielo.br/scielo.php?script=sci_arttext\&pid=S0103166X2016000100051\&lng=en\&nrm=iso >. Acesso em: 20 Nov. 2017.

FAVERO, M. A. B.; SANTOS, M. A. dos. Autismo infantil e estresse familiar: uma revisão sistemática da literatura. Psicol. Reflex. Crit., v. 18, n. 3, p. 358-369,Dez.2005. Disponível em: $<\mathrm{http}: / /$ www.scielo.br/scielo.php?script=sci_arttext\&pid=S0102$79722005000300010 \&$ Ing=en\&nrm=iso>. Acesso em: 20 Nov. 2017.

GOMES, P. T.M. et al. Autismo no Brasil, desafios familiares e estratégias de superação: revisão sistemática. J. Pediatr., v. 91, n. 2, p. 111-121, Abr. 2015. Disponível em: $<$ http://www.scielo.br/scielo.php?script=sci_arttext\&pid=S0021-

$75572015000200111 \&$ Ing=en\&nrm=iso >. Acesso em: 20 Nov.2017.

JERUSALINSKY, J. et al. Autismos e seus tratamentos: contribuições da metodologia psicanalítica nesse campo. Correio APPOA, 222/223, 25-45, 2013. Disponível em: <www.appoa.com.br/uploads/arquivos/correio/222.pdf>.Acesso em: 20 Nov. 2017.

KLIN, A. Autismo e síndrome de Asperger: uma visão geral. Rev. Bras. Psiquiatr.,v.28, supl. 1, p. s3-s11, Mai.2006. Disponível em: <http://www.scielo.br/scielo.php?script=sci_arttext\&pid=S1516$44462006000500002 \&$ Ing=en\&nrm=iso >. Acesso em: 20 Nov. 2017.

MAIA, F. A.et al. Importância do acolhimento de pais que tiveram diagnóstico do transtorno do espectro do autismo de um filho. Cadernos Saúde Coletiva, v. 24, n. 2, p. 228-234, AbrJun. $2016 . \quad$ Disponível em: $<$ http://www.scielo.br/scielo.php?script=sci_arttext\&pid=S1414462X2016000200228\&lng=en\&nrm=iso>. Acesso em: 20 Nov. 2017.

MINAYO, M. C. S. (Org.). Pesquisa Social: teoria, método e criatividade. Rio de Janeiro: Vozes, 2007.

OLIVEIRA, D. S. de et al. Interação vincular de pais com filhos autistas. Revista de Psicologia da Criança e do Adolescente, v. 5, n. 2, 2014. Disponível em: <http://revistas.lis.ulusiada.pt/index.php/cipca/article/view/659>. Acesso em: 20 Nov. 2017.

PINTO, R. N. M. et al. Autismo infantil: impacto do diagnóstico e repercussões nas relações familiares. Rev Gaúcha Enferm., v. 37, n. 3, p. 1-9, 2016. Disponível em:<http://www.scielo.br/pdf/rgenf/v37n3/0102-6933-rgenf-1983-144720160361572.pdf>. Acesso em: 20 Nov. 2017.

SCHMIDT, C.; DELL'AGLIO, D. D.; BOSA, C. A. Estratégias de coping de mães de portadores de autismo: lidando com dificuldades e com a emoção. Psicol. Reflex. Crit., v.20, n. 1, p. 124-131, $2007 . \quad$ Disponível em: <http://www.scielo.br/scielo.php?script=sci_arttext\&pid=S0102-

79722007000100016\&lng=en\&nrm=iso>. Acesso em: 20 Nov. 2017. 
SEGEREN, L.; FRANÇOZO, M. de F. de C. As vivências de mães de jovens autistas. Psicol. estud., v. 19, n. 1, p. 39-46, Mar. 2014. Disponível em: $<$ http://www.scielo.br/scielo.php?script=sci_arttext\&pid=S1413$73722014000100006 \&$ Ing=en\&nrm=iso>. Acesso em: 20 Nov. 2017.

SILVA, R. R.; CHAVES, E. F. Autismo: reações e consequências nas relações familiares. Encontro: revista de psicologia, v. 17, n. 26, p. 35-45, Jul. 2014. Disponível em: <http://pgsskroton.com.br/seer/index.php/renc/article/viewFile/2413/2315>. Acesso em: 20 Nov. 2017.

SMEHA, L. N.; CEZAR, P. K. A vivência da maternidade de mães de crianças com autismo. Psicologia em Estudo, v. 16, n. 1, p. 43-50, JanMar.2011.Disponível em: <http://www.scielo.br/pdf/pe/v16n1/a06v16n1>. Acesso em: 20 Nov. 2017. 